\title{
NUTRIÇÃO DE CÃES E GATOS EM SUAS DIFERENTES FASES DE VIDA
}

Ronaildo Fabino Neto, Mônica Maria de Almeida Brainer, Leticia Fernanda Xavier Costa, Luís Gustavo Silva Rodrigues, Antônio Roberto de Oliveira Junior, João Paulo Belém de Sousa

Instituto Federal Goiano Campus Ceres, Ceres, GO. E-mail: ronaildo.neto@ifgoiano.edu.br

\section{RESUMO}

O objetivo desta revisão é realizar um levantamento sobre os principais conceitos relacionados à nutrição de cães e gatos nas diferentes fases de vida. O mercado de produtos e serviços para animais de estimação vem se expandindo a nível mundial e caracteriza-se como um novo e lucrativo segmento da economia. Os avanços na pesquisa com nutrição de pets têm ocorrido para atender a uma demanda cada vez maior tanto na inovação de produtos que chamem a atenção dos proprietários e dos animais, como para assegurar o atendimento das exigências nutricionais em cada idade e uma melhor qualidade de vida. Cães e gatos apresentam-se como carnívoros, porém com hábitos e formas alimentares muitas vezes classificadas como de uma espécie onívora, sendo os gatos carnívoros estritos e os cães facultativos. Assim como a dieta humana, a saúde dos cães depende de uma alimentação correta e balanceada que contenha um amplo conjunto de nutrientes para suprir todas as necessidades diárias. Os alimentos funcionais englobam tanto alimentos quanto ingredientes que têm as funções nutricionais básicas e também produzem efeitos metabólicos e/ou fisiológicos benéficos à saúde. A adição de ingredientes funcionais aos alimentos de cães e gatos já é uma realidade na nutrição de pets. Além disso, há uma variedade de produtos alimentícios para cães e gatos, sendo classificados como secos, úmidos e semi-úmidos.

Palavras-chave: Alimentos Alternativos; Caninos; Felinos, Manejo Nutricional; Pets.

\section{NUTRITION OF DOGS AND CATS IN THEIR DIFFERENT STAGES OF LIFE}

\begin{abstract}
The objective of this review is to conduct a survey on the main concepts related to dog and cat nutrition in the different life stages. The market for pet products and services has been expanding worldwide and is a lucrative new segment of the economy. Advances in research with pet nutrition have occurred to meet a growing demand both for product innovation that catches the attention of owners and animals, as well as for ensuring that nutritional requirements are met at each age and a better quality of life. Dogs and cats present themselves as carnivores, but with habits and food forms often classified as an omnivorous species, with carnivorous cats being strict and dogs being facultative. Just like the human diet, dogs' health depends on a correct and balanced diet that contains a broad set of nutrients to meet all daily needs. Functional foods encompass both foods and ingredients that have the basic nutritional functions and also produce metabolic and / or physiological health benefits. The addition of functional ingredients to dog and cat foods is already a reality in the nutrition of pets. In addition, there are a variety of food products for dogs and cats, being classified as dry, moist and semi-moist.
\end{abstract}

Keywords: Alternative foods; Canines; Felines, Nutritional Management; Pets. 


\section{INTRODUÇÃO}

A relação entre o homem e os animais de estimação já se encontra estabelecida há séculos. Mesmo sem códigos de comunicação verbal inteligíveis, exceto as manifestações de afeto, os animais de estimação ou pets conquistaram lugar no consumo de massas só pelo fato de necessitarem e exigirem cuidados especiais (YABIKU, 2003).

Pesquisas científicas relacionadas à nutrição de animais de companhia, principalmente nos últimos 10 anos, deixaram de focar a dicotomia entre as necessidades mínimas e teores máximos, sobretudo quanto ao estabelecimento das recomendações nutricionais (CARCIOFI; JEREMIAS, 2010). O conhecimento das necessidades mínimas deixou de ser tão importante e, cada vez mais, busca-se entender o papel da nutrição na promoção de saúde, bem-estar e longevidade (YABIKU, 2003).

No início desta década foi formado um comitê pelo Conselho Nacional de Pesquisas Norte Americano para revisar as publicações sobre necessidades nutricionais de cães (Canis lupus familiaris) e gatos (Felis catus). Segundo Carciofi e Jeremias (2010) foi atribuída a esse comitê a tarefa de revisar estas publicações e transformá-las em um único documento, que veio a ser publicado em 2006, o NRC - Nutrient requirements of dogs and cats.

Antes do lançamento do NRC para cães e gatos havia apenas informações dispersas sobre a biodisponibilidade de nutrientes e necessidades nutricionais de animais de companhia. $O$ progresso na nutrição de cães e gatos exigia informações mais precisas sobre as necessidades das diversas fases da vida (especialmente a reprodução e manutenção), juntamente com os valores de biodisponibilidade dos nutrientes dos ingredientes das dietas (CAPPILLI et al., 2016).

A partir desta demanda pesquisadores e indústria de alimentos para cães e gatos têm respondido, redirecionando objetivos e métodos de pesquisa. A pesquisa nutricional tem, assim, se diversificado em objetivos abrangendo áreas como longevidade, gerontologia, bem-estar, imunidade, beleza de pelo e pela função digestiva, função cognitiva, saúde oral e prevenção de doenças degenerativas, dentre as quais se pode incluir o manejo nutricional de extenso número de condições como endocrinopatias, obesidade, distúrbios gastrointestinais, distúrbio alérgicos, entre outros (CARCIOFI, 2005; CARCIOFI, 2007; CARCIOFI, 2008 e CARCIOFI; JEREMIAS, 2010).

Segundo NRC (2006) o importante e correto conhecimento das fases de vida do animal ajuda a determinar, de maneira lógica, o manejo alimentar aplicado a estas fases visando um ótimo estado de saúde e qualidade de vida.

O objetivo desta revisão é realizar um levantamento sobre os principais conceitos relacionados à nutrição de cães e gatos nas diferentes fases de vida.

\section{COMPORTAMENTO ALIMENTAR DE CÃES E GATOS}

A base do consumo alimentar é genética, onde os animais, de certa forma atribuem conceitos de ingestão dos alimentos com base em seus antepassados e o período de domesticação (CAPPILLI et al., 2016). Em tempos remotos os animais ingeriam alimentos de uma forma incerta, visto que a quantidade também era irregular, muito diferente dos atuais manejos e formas alimentares (YABIKU, 2003).

Ogoshi et al (2015) afirmam que cães e gatos são animais anatomicamente carnívoros, pois apresentam caninos bem desenvolvidos, ausência de amilase salivar, estomago bastante desenvolvido e extremamente ácido. Apesar disso, ressaltam que mesmo assim, pela própria história evolutiva do cão, a sua dieta tem característica mais onívora enquanto que a do gato indica uma dieta mais carnívora.

Cães e gatos apresentam-se como carnívoros, porém com hábitos e formas alimentares muitas vezes classificadas como de uma espécie onívora. Silva Junior et al. (2006) ressaltam que há um senso comum em dizer que os cães são classificados como carnívoros não restritos e os gatos como carnívoros restritos. 


\section{EXIGÊNCIA ALIMENTAR DE CÃES E GATOS}

Assim como a dieta humana, a saúde dos cães depende de uma alimentação correta e balanceada que contenha um amplo conjunto de nutrientes para suprir todas as necessidades diárias, são eles: proteínas, gorduras, carboidratos, vitaminas, minerais, e água (CAPPILLI et al., 2016).

De acordo com Yabiku (2003) é importante também a adição de ingredientes funcionais como prebióticos, fibras especiais, auxiliadores da saúde articular, entre outros, que promovem a saúde, bem-estar e contribuem para uma maior longevidade.

Outro fator que se deve levar em conta na dieta dos cães é a idade e o estilo de vida, com o objetivo de promover um equilíbrio nutricional nas diferentes fases. Segundo o NRC (2006), os cães atletas ou muito agitados geralmente necessitam de alimentos ricos em nutrientes com alto valor energético, já os castrados e sedentários precisam ter a dieta adaptada ao estilo de vida. 0 nível reduzido de atividade física precisa ser equilibrado com uma alimentação de baixo teor calórico e de nutrientes especiais para apoiar esta condição (YABIKU, 2003).

A falta ou excesso de nutrientes pode desequilibrar o sistema fisiológico do animal e predispor o organismo ao mau desenvolvimento corporal e constituição óssea, obesidade, alterações reprodutivas, dentre outros (CARCIOFI, 2005). Uma alimentação adequada ao cão filhote, por exemplo, propicia boas condições para sua saúde e consequentemente para seu desempenho futuro (CARCIOFI; JEREMIAS, 2010).

No entanto, os gatos possuem características peculiares em relação ao manejo e dieta, sendo de extrema importância uma atenção especial quanto à alimentação para garantir uma melhor saúde e bem-estar (CARCIOFI, 2008).

De acordo com Cappilli et al. (2016), devido ao metabolismo específico, estes animais têm necessidades nutricionais diferentes dos cães, como: maior exigência proteica; assim como do aminoácido arginina, da vitamina B6 e da niacina (respectivamente cerca de duas, três e quatro vezes maiores em relação aos cães); ingestão de vitamina A pré-formada na dieta e dificuldade em digerir carboidratos.

Apesar dos gatos serem considerados fisiologicamente carnívoros por necessitarem de nutrientes específicos, os quais só são encontrados na carne; com o advento do avanço nas tecnologias de processamento dos alimentos, como a extrusão, é permissível o uso de ração na alimentação dos felinos contendo uma grande fração de carboidrato, porém respeitando o equilíbrio dos nutrientes (SILVA JÚNIOR et al., 2006).

Vale ressaltar que os gatos não conseguem sintetizar o ácido araquidônico (um ácido graxo da família ômega 6) e o aminoácido taurina, sendo fundamental que estejam presentes na dieta. A alimentação quando filhote é de suma importância, pois é o período em que acontece o desenvolvimento de todos os tecidos e órgãos. Na fase adulta é necessário oferecer um alimento que contenha todos os nutrientes necessários para o bom desenvolvimento e manutenção do animal (CARCIOFI, 2005; CARCIOFI, 2008).

\section{ALIMENTOS FUNCIONAIS}

Os alimentos funcionais englobam tanto alimentos quanto ingredientes que cumprem as funções nutricionais básicas ao serem ingeridos, e vão além, produzindo efeitos metabólicos e/ou fisiológicos e/ou efeitos benéficos à saúde. Estes alimentos demonstram ser capazes de controlar funções corporais no sentido de auxiliar na proteção contra enfermidades como câncer, osteoporose, doenças coronárias, entre outras (SOUZA et al., 2003; BORGES et al., 2011).

A nutrição de cães e gatos, atualmente tem-se equiparado à nutrição dos humanos, com a adição de ingredientes funcionais aos alimentos. Esses alimentos são formulados ou modificados pela inclusão de fibras, prebióticos, probióticos, ácidos graxos poliinsaturados e os minerais 
quelatados (BORGES et al., 2011).

\section{Fibras}

Em um passado não muito remoto, a importância da fibra na alimentação de animais monogástricos era questionada, pois acreditava-se que possuía função apenas na formação do bolo fecal e na manutenção do trânsito intestinal, com efeitos sobre a diluição da energia e redução na digestibilidade dos demais nutrientes. Portanto, era considerada apenas uma substância inerte nas rações de carnívoros e onívoros e a sua quantificação nos alimentos tinha o objetivo de estabelecer o limite máximo de inclusão de ingredientes (ROQUE et al., 2006).

A fibra dietética apresenta dois conceitos um fisiológico e outro químico. O conceito fisiológico descreve a fibra dietética como indisponível para fonte energética, por ser um componente dos alimentos que não sofre hidrólise pelas enzimas digestivas dos mamíferos. Já o conceito químico define a fibra dietética como um polissacarídeo não amiláceo e lignina (FISCHER, 2011).

Quanto às propriedades físico-químicas, a fibra alimentar é dividida em insolúvel e solúvel em água. As fibras insolúveis sofrem fermentação na flora intestinal de forma muito reduzida e são responsáveis por aumentar e dar consistência à massa fecal e aumentar o peristaltismo intestinal. Já as solúveis servem como substrato para a fermentação no cólon, aumenta a viscosidade do bolo alimentar e assim reduzem o esvaziamento gástrico (MAIORKA e OLIVEIRA, 2014)

Os principais ácidos graxos voláteis (AGV) produzidos durante a fermentação das fibras são o acetato, propionato e o butirato. O principal efeito direto da produção de AGV relaciona-se com a acidificação do cólon que contribui para evitar a proliferação em demasia de bactérias indesejadas. Animais que recebem fibras moderadamente fermentáveis apresentam cólon com uma área maior e hipertrofia da mucosa, otimizando a digestibilidade dos nutrientes (BORGES et al., 2011).

O NRC (2006) não estabelece nenhuma recomendação com relação aos teores mínimos de fibra e nenhum limite que deve conter nos alimentos destinados a cães e gatos. A grande maioria dos alimentos comercializados contém um teor entre 1 e $4 \%$ da matéria seca, exceto os produtos com fins terapêuticos.

A inclusão de fibra na dieta de cães é hoje reconhecida como necessária para a manutenção da saúde do trato gastrointestinal, além da prevenção de doenças como o câncer de cólon. Apesar de poucos nutricionistas considerarem a importância da fibra na nutrição e carnívoros, já existem alimentos comerciais contendo fibras dentro dos parâmetros estudados.

\section{Probióticos e Prebióticos}

Os probióticos são microrganismos vivos adicionados aos alimentos, que ao serem fornecidos continuamente na dieta, afetam de forma benéfica o organismo animal no desenvolvimento da microbiota intestinal. São utilizados a fim de evitar infecções entéricas e gastrointestinais. Os microrganismos empregados como probióticos são integrantes não patogênicos da flora microbiana normal, como as bactérias ácido-lácticas e leveduras (ANFALPET, 2010).

Segundo França et al. (2011), esses microrganismos atuam para desfavorecer a colonização da microbiota intestinal por microrganismos patogênicos como a Salmonella, Escherichia coli e outros patógenos potenciais. Estes microrganismos também sintetizam vitaminas, enzimas e ácidos graxos voláteis, que podem ter efeito benéfico sobre a saúde gastrintestinal, e ajudam na absorção de nutrientes.

Resultados positivos são encontrados relacionados a utilização dos probióticos nas dietas 
de animais de produção. Feliciano et al. (2009) avaliaram os efeitos da suplementação de dois tipos de probióticos para cães filhotes que receberam dois tipos de dieta, de alta e de baixa qualidade, e verificaram que o probiótico contendo Bifidobacterium e Lactobacillus apresentou efeitos positivos no trato gastrointestinal, principalmente quando administrado junto com dietas de menor qualidade.

Contudo, em se tratando de cães e gatos os efeitos são variáveis e ainda não foram totalmente comprovados. Outra problemática relaciona-se com a dificuldade no processamento, pois os alimentos secos são extrusados e passam por altas temperaturas por poucos segundos $\left(180^{\circ} \mathrm{C}\right)$ o que já é suficiente para matar os microrganismos. Logo, os probióticos devem ser adicionados após a extrusão (BORGES et al., 2011).

Os prebióticos são oligossacarídeos não digeridos no organismo animal, mas seletivamente fermentados pelos microrganismos do trato gastrintestinal (TGI) que podem estar presentes nos ingredientes da dieta ou adicionados a ela através de fontes exógenas concentradas (SILVA; NORNBERG, 2003).

O principal papel dos prebióticos é promover o desenvolvimento e/ou ativar o metabolismo de determinado grupo de bactérias benéficas ao trato intestinal. Atuam bloqueando os sítios de aderência e assim paralisando e diminuindo a capacidade de fixação de algumas bactérias patogênicas na mucosa intestinal. O êxito desses compostos é dependente da sua não hidrolização pelas enzimas digestivas, o que possibilita chegarem sem danos ao intestino grosso onde são fermentados pelos microrganismos ali presentes. Os prebióticos mais empregados na alimentação animal são os mananoligossacarídeos (MOS), os frutoligossacarídeos (FOS) e os glucoligossacarídeos (GOS) (BRITO, et al., 2014).

Segundo Silva e Nornberg (2003), os prebióticos são compostos biologicamente seguros à saúde humana e animal, justificando o seu uso alternativo em substituição a antibióticos promotores de crescimento. Entretanto, seus efeitos nem sempre são comprovados devido a vários fatores, tais como, composição química dos demais ingredientes, dosagem usada ou estresse dos animais.

\section{Ácidos graxos poliinsaturados}

Os ácidos graxos são fontes energéticas de grande importância para os animais carnívoros, como os cães e os gatos. Eles também possuem função estrutural importante nos organismos vivos, na forma de fosfolipídios, como constituintes das membranas celulares, são também cofatores enzimáticos, transportadores de eletrons, pigmentos fotossensíveis, ancoras hidrofóbicas para proteínas, agentes emulsificantes no trato digestivo, hormônios e mensageiros intracelulares (TREVIZAN; KESSLER, 2009; NELSON; COX, 2011).

De acordo com Nelson e Cox (2011) os ácidos graxos podem ser classificados como ácidos graxos poli-insaturados, os quais são ácidos carboxílicos com cadeias hidrocarbonadas de comprimento variado, contendo mais de uma dupla ligação, apresentando-se na forma líquida em temperatura ambiente, o que é favorável ao sistema circulatório.

$\mathrm{Na}$ dieta de cães e gatos é de suma importância suprir os ácidos graxos poli-insaturados denominados de Ômega 3 (Ácido alfa-linolênico) e os Ômega 6 (Ácido Linoleico e Araquidônico), pois esses ácidos são considerados essenciais, ou seja, o organismo é incapaz de sintetizá-los (WORTINGER, 2009).

Além disso, os ácidos graxos linoleicos são precursores de vários ácidos graxos, sendo essencial para manter as estruturas apropriadas para as membranas, o crescimento normal, a manutenção do estado da pele, como a regulação da permeabilidade da água, e o transporte de lipídeos pelo sangue. Já o ácido araquidônico é essencial, principalmente para os gatos, na formação de eicosanóides, que afetam diretamente nas funções reprodutoras (CASE, et al., 1998).

Segundo Wortinger (2009) os cães têm mecanismos que conseguem converter o ácido 
linoleico em araquidônico ou em gama-linolênico, assim se fornecido ácido linoleico em quantidades adequadas, pode suprir as necessidades de ácido araquidônico e gama-linolênico. Já os gatos requerem uma fonte de ácido araquidônico na dieta, pois falta atividade da enzima deltadesaturase, que é produzida pelas células do fígado, assim são incapazes de fazer conversões de ácido linoleico em araquidônico.

De acordo com Case et al., (1998) gatas gestantes que não recebem ácido araquidônico apresentam alterações das plaquetas e trombocitopenia, podendo ocasionar nos gatos também ligeira mineralização dos rins, atraso no crescimento, deterioração na cicatrização de feridas, e desenvolvimento de lesões cutâneas.

Estes ácidos graxos são encontrados em óleos vegetais e estão presentes em níveis significativos em vísceras de animais e derivados de peixes, de forma que seu conteúdo usual em alimentos comerciais, feitos a partir de ingredientes vegetais, carne e subprodutos de animais, são normalmente baixos, mas suprem as exigências (TREVIZAN; KESSLER, 2009).

\section{Minerais quelatados}

De acordo com Wortinger (2009) os minerais são a porção inorgânica da dieta, sendo utilizados pelo organismo como componentes estruturais, como porções dos líquidos corpóreos e como eletrólitos cofatores de sistemas enzimáticos e hormonais.

Os minerais podem ser denominados como quelatados, ou seja, são todos os compostos formados por íons metálicos sequestrados por substâncias orgânicas como aminoácidos, peptídeos ou complexos polissacarídeos que proporcionam a esses íons alta disponibilidade biológica, alta estabilidade e solubilidade. (KIEFER, 2005).

A maioria dos alimentos para cães e gatos fornecem os minerais em sua forma simples (não quelatada), sendo assim a maioria dos elementos minerais, para serem absorvido, devem fazer uma ligação iônica com os aminoácidos que se encontram livres no estômago e intestino, ou aqueles presentes na membrana das células do trato intestinal, assim frequentemente ocorrem competições de diferentes minerais para se ligarem aos mesmos aminoácidos, contudo impedindo que alguns minerais sejam absorvidos (BORGES et. al., 2011).

No entanto o uso de minerais quelatados nas dietas de cães e gatos diminuem os riscos da não absorção, pois entram no trato intestinal já ligados aos ligantes, assim o mineral quelatado é absorvido pelo organismo e nele se mantém intacto, ou seja, as suas ligações com seus ligantes permanecem inalteradas (BORGES et. al., 2011).

\section{TIPOS DE RAÇÕES PARA ANIMAIS DE ESTIMAÇÃO}

No Brasil a indústria de rações destinadas aos cães e gatos teve um crescimento satisfatório nos últimos anos. A produção do país passou de 1,15 para 1,93 milhões de toneladas somente entre os anos de 2001 e 2009, respectivamente o que representou um aumento de $68 \%$ em apenas 8 anos (SINDIRAÇÕES, 2009).

Até o princípio do século $\mathrm{XX}$, a alimentação dos animais de estimação se restringia aos restos da alimentação de seu proprietário. Com o início da produção de rações comerciais as opções nos mercados só têm se expandido. Hoje a grande maioria dos proprietários de cães e gatos só alimentam seus animais com rações comerciais no lugar de dietas caseiras (WORTINGER, 2009).

A classificação geral dos alimentos comerciais para os animais de estimação é feita de acordo com a fabricação, os métodos de conservação e a quantidade de umidade. Estas categorias compreendem: os alimentos secos, os enlatados e os semiúmidos (CASE, et al., 1998).

\section{Alimentos Secos}

Os alimentos secos ou desidratados destinados aos animais de estimação apresentam 
entre 6 e 10\% de umidade e 90\% ou mais de matéria seca. Estes alimentos são vendidos sob a forma de biscoitos, farinhas, pedaços triturados e pellets expandidos e extrusados. Os alimentos comumente empregados incluem cereais em grãos, produtos de carne, aves ou peixes, alguns produtos lácteos e suplementos vitamínicos e minerais (CASE et al., 1998; WORTINGER, 2009).

Os carboidratos nestas dietas correspondem a mais de $50 \%$ da formulação, sendo responsáveis por 30 a $60 \%$ da energia metabolizável (EM). A grande maioria das dietas produzidas no Brasil são extrusadas. Essas dietas apresentam como maior vantagem sua facilidade de conservação, manuseio e custo (FORTES, 2005).

Ainda de acordo com Fortes (2005), o processo de conservação das dietas secas está relacionado à baixa umidade em conjunto aos antioxidantes, antifúngicos e acidificantes. Outro aspecto importante é o uso de embalagens adequadas, que impedem a entrada de água, oxigênio e luz no produto, prologando sua vida de prateleira.

Segundo Wortinger (2009) as rações secas contêm maior teor de nutrientes e energia por unidade de peso quando comparadas com as de maior conteúdo de umidade. Com relação a densidade calórica os alimentos secos apresentam entre 3.000 e 4.500 Kcal de EM/kg. Quantitativamente os alimentos destinados aos gatos, possuem uma densidade energética pouco maior que a dos cães.

Uma das desvantagens dos alimentos secos relaciona-se com sua menor palatabilidade, especialmente os produtos com baixo percentual de gorduras ou com ingredientes de escassa digestibilidade. Mas nos últimos anos a indústria alimentícia de pets tem se preocupado, na busca por ingredientes de alta qualidade, com muito sabor e digestibilidade (CASE, et al., 1998).

\section{Alimentos úmidos}

As rações úmidas estão disponíveis no mercado de forma enlatada, em sachês e bandejas de plástico. O teor de umidade nestes alimentos varia entre 72 e $85 \%$. Estas rações podem fornecer desde uma alimentação completa e equilibrada, servir como alimento suplementar ou petisco saboroso (WORTINGER, 2009). Os alimentos úmidos de alta qualidade devem atender as exigências nutricionais do NRC (NATIONAL RESEARCH COUNCIL) e do WALTHAM (CENTRE FOR PET NUTRITION) (WALTHAM, 2007).

Os alimentos mais empregados na produção de rações úmidas incluem: carnes, carne mecanicamente separada, vísceras de frango, peixes, farinha de soja, amido de milho, pectinas, gomas entre outros. Com relação ao processo de fabricação estes são preparados sob temperatura e pressão elevadas para eliminação de bactérias nocivas o que thes confere largos períodos nas prateleiras. Normalmente são produtos caros devido a todo o processamento necessário, elevado teor de água e tipo de embalagem (CASE, et al., 1998; FORTES, 2005).

Segundo Waltham (2007) os alimentos úmidos apresentam entre 60 e $130 \mathrm{Kcal} / 100 \mathrm{~g}$ enquanto que os alimentos secos por volta de $350 \mathrm{Kcal} / 100 \mathrm{~g}$. Algumas das vantagens dos alimentos úmidos são:

- Contribui para a manutenção do balanço hídrico ótimo do organismo animal;

- Textura ideal, é mais facilmente mastigado e engolido, principalmente por filhotes e animais idosos; e

- Níveis próximos dos ótimos para a concentração de macronutrientes tanto para cães quanto para gatos.

\section{Alimentos semiúmidos}

Os alimentos semiúmidos apresentam entre 15 e $30 \%$ de água, e os ingredientes comumente utilizados são tecidos animais congelados ou frescos, cereais, gorduras e açúcares simples. Para conservação destas rações são empregados umectantes como açúcares, sais e glicerol e outros conservantes. Por conterem alta percentagem de açúcares simples possuem 
maior sabor e digestibilidade. Embora alimentos com teores de açúcares simples mais elevados sejam mais atrativos para cães do que para os gatos (CASE, et al., 1998).

$\mathrm{O}$ conteúdo de EM dos alimentos semiúmidos varia entre 3.000 e $4.000 \mathrm{Kcal} / \mathrm{Kg}$ de matéria seca. E com relação ao teor proteico estas rações apresentam entre 20 e $28 \%$ e entre 8 e $14 \%$ de gorduras, tomando como base a matéria seca (WORTINGER, 2009).

O processo de conservação destes produtos ocorre através de umectantes, antioxidantes, baixo $\mathrm{pH}$, antifúngicos e baixa umidade. Por causa destes quesitos as embalagens das rações semiúmidas são relativamente mais caras quando comparadas as das rações secas, pois as mesmas devem evitar a perda de água que prejudicaria a plasticidade e palatabilidade do produto (FORTES, 2005).

\section{ALIMENTAÇÃO POR FASES DA VIDA DOS CÃES \\ Cães Neonatos}

As 48 horas iniciais pós-parto são os momentos primordiais para o desenvolvimento e crescimento para toda a vida do animal. Para esse período é necessário que as fêmeas forneçam o alimento inicial, o colostro, tendo como função de alimentar e imunizar os filhotes. Após as primeiras 48 horas o leite perde a capacidade de imunizar, desenvolvendo somente a função de alimento (LAZZAROTTO, 2000).

Nas quatro primeiras semanas, os filhotes devem se alimentar por volta de 3 a 6 vezes por dia. A ingestão intensa de leite materno ajuda a minimizar as enfermidades e proporciona um melhor desenvolvimento inicial. Em média após a 5a semana os filhotes necessitam de uma suplementação alimentar, esses suplementos são comercialmente produzidos por várias empresas para serem oferecidos até o desmame.

De acordo com Bordin (2014), esse oferecimento deve seguir as orientações dos fabricantes, tendo como condições básicas:

- Umidificar estes alimentos com água morna, facilitando a ingestão;

- Ofertar por no máximo 30 minutos;

- Não adicionar leite de outros animais;

- Período médio de desmame por volta de 45 dias de idade.

\section{Cães em Crescimento}

Após o desmame os animais deverão se adaptar a uma nova realidade, sem a mãe e uma nova dieta alimentar, com somente alimentos processados. O período de crescimento dos animais podem variar de 7 a 12 meses iniciais, dependendo do porte da raça. Conforme o proposto por Bordin (2014), raças caninas de grande porte, como Dogue Alemão, estabiliza seu ganho de peso por volta dos 12 meses de idade com peso próximo aos $80 \mathrm{~kg}$, enquanto cães de pequeno porte, como o Poodle Miniatura, estabiliza o seu ganho de peso por volta dos seis meses com aproximadamente três quilos.

A intensidade de ganho de peso e desenvolvimento são de 35 vezes o peso inicial para o peso adulto. Deve-se observar que o crescimento deve ser de forma definitiva e equilibrada. Recomenda-se a utilização de dietas formuladas específicas para esta fase da vida do animal, associando o fornecimento de alimentos ideal ao crescimento animal, a fim de desenvolver os constituintes orgânicos de forma equilibrada (LAZZAROTTO, 2000).

$O$ rápido crescimento de raças de grande porte, predispõe o surgimento de problemas ósseos, assim com o fornecimento de uma dieta equilibrada nutricionalmente, minimiza o desenvolvimento dessas enfermidades. As necessidades energéticas podem ser calculadas conforme a Tabela 1: 
Tabela 1. Cálculo das necessidades energéticas de cães em crescimento:

\begin{tabular}{|c|c|c|}
\hline Idade & $\begin{array}{r}\text { Valor } \\
\text { de K }\end{array}$ & Exemplo \\
\hline \multicolumn{3}{|c|}{ Raça pequena e média } \\
\hline $6-11$ & 375 & Filhote de 3,17 kg: $375 \times 3^{0,67}=404 \mathrm{kcal} / \mathrm{dia}$ \\
\hline \multicolumn{3}{|r|}{ 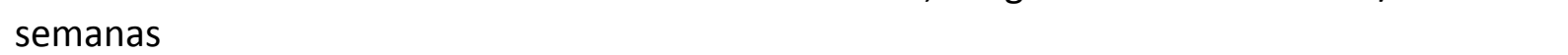 } \\
\hline $3-4$ & 350 & Filhote de 6,34 kg: $350 \times 6,4^{0,67}=1.214 \mathrm{kcal} / \mathrm{dia}$ \\
\hline \multicolumn{3}{|r|}{ 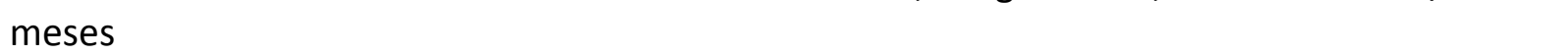 } \\
\hline $5-7$ & 225 & Filhote de $8,15 \mathrm{~kg}: 225 \times 8,2^{0,67}=921 \mathrm{kcal} / \mathrm{dia}$ \\
\hline meses & & \\
\hline \multicolumn{3}{|l|}{ meses } \\
\hline \multicolumn{3}{|c|}{ Raça grande e gigantes } \\
\hline $6-11$ & 340 & Filhote de $7,25 \mathrm{~kg}: 340 \times 7,3^{0,67}=1288 \mathrm{kcal} / \mathrm{dia}$ \\
\hline semanas & & \\
\hline meses $^{3-4}$ & 300 & Filhote de $15,4 \mathrm{~kg}: 300 \times 15,4^{0,67}=1.874 \mathrm{kcal} / \mathrm{dia}$ \\
\hline meses $^{5-7}$ & 200 & Filhote de $22,6 \mathrm{~kg}: 200 \times 22,7^{0,67}=1.620 \mathrm{kcal} / \mathrm{dia}$ \\
\hline meses ${ }^{8-12}$ & 160 & Cachorro de 26,3 kg: $160 \times 26,4^{0,67}=1.432 \mathrm{kcal} / \mathrm{dia}$ \\
\hline meses ${ }^{12-24}$ & 132 & Cachorro de $29 \mathrm{~kg}: 132 \times 29^{0,67}=1.260 \mathrm{kcal} / \mathrm{dia}$ \\
\hline
\end{tabular}

Fonte: BORDIN, 2014

Na prática alguns elementos alimentares devem ser observados:

- Dieta altamente digestível, completa e balanceada para o crescimento;

- Determinar um manejo alimentar controlado no fornecimento de alimentos - 3 refeições diárias; crescimento;

- Relacionar o crescimento ao tipo de alimento fornecido - dieta X curva de

- Raças grandes e gigantes não devem apresentar níveis suplementares de cálcio, além dos níveis da dieta ofertada;

- Um esquema de exercícios deve ser estipulado durante o crescimento.

(WOLFARTH et al., 2011)

\section{Cães Adultos}

Cães adultos, são os animais que não estão em nenhum estado reprodutivo ou em atividade intensa e, nesse caso, deve-se adequar uma dieta alimentar completa e balanceada sem ultrapassar os níveis ideais de energia, para evitar problemas de obesidade (SÁ, 2002).

Em um contexto geral, os animais que estão em um estado de manutenção podem apresentar uma vida condicionada e restrita, e recomenda-se o fracionamento da alimentação em três refeições diárias. Nesse caso utiliza-se uma fórmula para calcular a necessidade energética desses animais (BORGES et al., 2011).

\section{$\mathrm{NEM}=\mathrm{K} \times \mathrm{P}^{0.67}$}


Onde:

- $\quad \mathrm{NEM}=$ necessidade energética

- $\mathrm{P}=$ peso vivo do animal em $\mathrm{kg}$,

- $\mathrm{K}=99$ - inativos; 132 - ativos; ou 160 - grande atividade.

Outro fator de suma importância é a oferta de água fresca e à vontade aos animais, pois todos os processos metabólicos necessitam de hidratação.

\section{Cães Idosos}

Com a expectativa de vida dos cães, deve-se observar os padrões nutricionais e de saúde desses animais. Quando equilibrada a nutrição desses animais, possibilita melhor qualidade de vida, reduzindo os possíveis problemas metabólicos em função da idade avançada (BORGES et al., 2011).

As diferenças de raças, porte e ritmos de vida, podem variar os parâmetros de velhice dos animais, recomenda-se observar cada animal em especial. Algumas reações clínicas são notadas em cães idosos como: diminuição da constituição de tecido muscular magro, aumento da quantidade de gordura corpórea, problemas articulares variáveis, diminuição da quantidade de água corporal (SÁ, 2002).

De acordo com Bordin et al. (2014) alguns pontos devem ser observados para uma melhor alimentação destes animais:

- Consultas, revisões clínicas e nutricionais ao menos 2 vezes ao ano;

- Manter uma dieta adequada e balanceada para idosos;

- Valor proteico da dieta, com alta qualidade e mais digestível;

- Regular a quantidade de alimento e energia ingerida;

- Evitar a obesidade;

- Atividade física associada à nutrição, ambos equilibrados;

- Dietas terapêuticas podem ser recomendadas.

\section{ALIMENTAÇÃO POR FASES DA VIDA DOS GATOS \\ Gatos Neonatos}

A primeira semana de vida dos gatos é extremamente crítica e irá definir seu desenvolvimento ao longo de sua vida, pois esses animais são fisiologicamente e neurologicamente imaturos, tendo baixas porcentagens de gordura corpórea. Contudo, são preconizados alguns cuidados essenciais, principalmente no que desrespeito a alimentação, para o bom desenvolvimento dos recém-nascidos (WORTINGER, 2009; CASE et. al, 1998).

0 principal alimento que o recém-nascido deve receber nas primeiras 24 às $72 \mathrm{~h}$ é o colostro, no qual agregara imunidade, devido os anticorpos presentes, além de ser rico em proteína e gordura que iram suprir a demanda nutricional do animal (WORTINGER, 2009).

Os gatos recém-nascidos devem permanecer com as mães, já os rejeitados devem ser aleitados separadamente com leite comercial destinado a espécie, de 4 a 6 vezes ao dia. No entanto deve se atentar aos cuidados sanitários com animais órfãos, pois o leite comercial não fornece anticorpos, sendo que esses animais são mais susceptíveis a doenças, pois geralmente não mamaram o colostro (WORTINGER, 2009).

Prats (2005) desenvolveu uma formula caseira para formular sucedâneo do leite felino no qual é uma ferramenta opcional na falta de sucedâneo do leite formulado industrialmente. A receita é composta de $90 \mathrm{~mL}$ de leite condensado, $120 \mathrm{~mL}$ de iogurte integral, três a quatro gemas de ovos e $90 \mathrm{~mL}$ de água.

Segundo Case et. al. (1998) os alimentos sólidos podem ser introduzidos na $3 \underline{a}$ ou $4 \underline{a}$ semana de vida, sendo ofertado juntamente com leite ou água morna para amolecer e facilitar a 
ingestão. A quantidade de leite ou água deve diminuir gradativamente até a 5 a semana, na qual pode ser ofertado o alimento completamente sólido.

\section{Gatos em Crescimento}

A fase de crescimento e desenvolvimento é relativamente curta o que se dá quando os gatos atingem a maturidade com média de 45 vezes o peso ao nascimento. Para garantir um crescimento com um tamanho normal para os filhotes, é necessário garantir uma dieta bem equilibrada (CASE, et al., 1998).

Ainda Case et al., (1998), ressalta que no período de crescimento os gatos necessitam de uma quantidade superior de energia metabolizável (EM) do que a exigida para a manutenção dos gatos adultos. Mesmo que um gato adulto ativo necessite de $70 \mathrm{kcal}$ de EM por $\mathrm{kg}$ de peso corporal, os gatos na fase de crescimento necessitam de, no mínimo, $160 \mathrm{kcal}$ de EM por kg de peso corporal durante todo o período de seu crescimento.

Segundo Seixas et al. (2003), os gatos em crescimento necessitam de mais alimentos ricos em proteína que os gatos adultos devido a formação dos novos tecidos associado à fase de crescimento. A proteína desse alimento deve ser de alta qualidade e de fácil digestão, para garantir a liberação de todos os aminoácidos essenciais para o crescimento e desenvolvimento.

A crença que se deve adicionar cálcio e fósforo nas rações para os gatos e cães não é justificada pelos perfis nutricionais recomendados pela Association of America Feed Control Official (AAFCO), pois a quantidade de cálcio e fósforo exigido pelo organismo desses animais na fase de crescimento é muito baixa (1\% para cálcio e $0,8 \%$ para fósforo). É sabido que as rações comercializadas contêm níveis desses dois elementos acima do recomendado, fornecendo assim mais do que o suficiente para esses animais em crescimento (WORTINGER, 2009).

Wortinger (2009) ressalta que, os cães e gatos ao serem levados para um novo lar após o desmame, normalmente são submetidos a uma nova ração. Porém essa mudança deve ser feita de forma gradual a partir do terceiro dia, com o fornecimento da mesma ração consumida antes de deixar a mãe.

Os felinos apresentam um comportamento alimentar que os diferenciam dos cães principalmente na fase de crescimento. A sua alimentação consiste no consumo frequente de pequenas quantidades de alimento ao longo do dia. Sendo assim, quanto mais ativo o gato mais frequente será sua alimentação podendo ser fornecida como dieta de livre escolha ou ad libitum (WORTINGER, 2009).

\section{Gatos adultos}

Segundo Case et al. (1998) diferente dos cães, os gatos não são animais vorazes, pois possuem o hábito de se alimentar durante várias vezes ao dia em pequenas porções e manter um peso ideal, podendo ser submetidos a uma dieta ad libitum. (WALTHAM, 2007).

Case et al. (1998) considera como gatos adultos aqueles que não estão em período de gestação, lactação ou trabalho ativo. Geralmente eles atingem sua fase adulta aos 10 e 12 meses de idade paralisando seu peso aos 18 meses. A manutenção da fase adulta geralmente vai dos 12 meses aos oito anos de vida. Para esses animais em manutenção adulta, a alimentação deve conter as seguintes características básicas, como:

- Proporcionar quantidade e a disponibilidade correta de nutrientes para manter a saúde física, mental e as atividades;

- Favorecer o melhor estado de saúde e, dessa maneira, reduzir a suscetibilidade a doenças;

- Ser suficientemente rica em nutrientes para permitir que o animal supra as suas exigências nutricionais ao se alimentar e;

- Ser suficientemente saborosa para assegurar um consumo adequado.

Os gatos não necessitam de amplas variedades de rações, basta ração de boa qualidade 
para suprir as necessidades nutricionais e uma boa disponibilidade de água. O que ocorre, é que muitos proprietários condicionam os animais a maus hábitos alimentares. A mudança frequente de dieta pode causar problemas gástricos produzindo disenteria e vômito (WORTINGER, 2009).

Wortinger, (2009) comenta que, as exigências nutricionais diárias de gatos castrados são reduzidas em 24 a 33\% quando comparada as de gatos inteiros. Essas reduções nutricionais se dão pela redução da taxa metabólica basal, pois os gatos castrados não diminuem as suas atividades.

\section{Gatos idosos}

A capacidade funcional dos órgãos dos gatos começa a cair logo depois que ele atinge a idade adulta, o que corresponde ao terço final da vida. Ruiz (2013) ressalta que, os diferentes sistemas que constituem o organismo começam a envelhecer em velocidades diferentes, sendo essa velocidade dependente de muitos fatores relacionados a vida do animal, como a genética, o ambiente e a alimentação.

Os animais idosos necessitam dos mesmos nutrientes que necessitavam nas fases de vida anteriores, porém, em proporção e quantidades diferentes, alguns mais e outros menos, como a energia metabolizável (em menor quantidade). A proteína também deve ser fornecida em menor quantidade e deve ser de qualidade elevada, para garantir melhor digestibilidade (CASE, et al., 1998).

A falência renal crônica e o hipertiroidismo são as doenças mais comuns em gatos idosos. Para amenizar o surgimento desses problemas da idade, deve se ter maior cuidado com a higiene oral, assim como, a disponibilidade de água limpa (CAMILO et al., 2014).

Segundo Ruiz (2013), à medida que os gatos vão envelhecendo, cai a sua eficiência digestiva, principalmente para os lipídios e proteínas. Com isso, nota-se que os gatos com função digestiva comprometida, tem tendência em aumentar o consumo diário de alimento, com o objetivo de compensar o efeito descrito anteriormente.

A recomendação aos proprietários é que continuem fornecendo a mesma quantidade de ração aos gatos quando atingem o terço final da vida, porém esses alimentos devem ser de alta digestibilidade, principalmente para proteína e lipídios (Case, et al., 1998).

\section{GESTAÇÃO E LACTAÇÃO DE CÃES E GATOS}

Segundo Cappilli et al. (2016) as fases destinadas à reprodução de cães e gatos são fases que requerem maior atenção alimentar, pois além das fêmeas, os filhotes que estão sendo gestados ou mesmo lactentes, necessitam de uma nutrição adequada para o desenvolvimento de ambos. A fêmea necessita de uma capacidade de manutenção e desenvolvimento dos filhotes e condições alimentares e ambientais para a lactação.

Os filhotes necessitam de condições para o correto desenvolvimento embrionário e após o nascimento, para o seu crescimento. Segundo Carciofi e Jeremias (2010) alguns fatores básicos são recomendados durante a gestação e lactação, como:

a) Durante a gestação:

- Alimentos de alta digestibilidade e específico para a fase;

- Valores energéticos controladas até a quinta semana;

- No terço final da gestação - pequenas porções diárias;

- Valorizar o conceito nutricional pela fase fisiológica;

- Observar ganho de peso das fêmeas - 20\% na média;

b) Durante a lactação:

- Alimentos de alta digestibilidade e específico para a fase;

- Administrar quantidade e qualidade energética evitando perda de peso;

- Fornecer duas vezes o valor de energia de manutenção para a fêmea evitar emagrecimento; 
- Água limpa e a vontade sempre;

- Redução do consumo a partir da $3^{\circ}$ semana de lactação.

Ao final da lactação os animais devem receber uma dieta que possibilite a recuperação corpórea e reprodutiva da fêmea (CARCIOFI, 2005; CARCIOFI, 2007). No período de desmame a redução alimentar é realizada para evitar a intensa e contínua produção láctea desnecessária, podendo gerar problemas com as mamas - mastites (CARCIOFI; JEREMIAS, 2010).

Outro ponto a ser considerado é a perda de peso durante a lactação, fato este que não pode ser maior que $10 \%$ do peso corpóreo normal da fêmea. A complementação alimentar com cálcio nas dietas não deve ser realizada, as dietas industriais fornecidas nesta fase são completas e balanceadas, podendo esta suplementação gerar problemas fetais com inadequado desenvolvimento (CARCIOFI, 2007).

\section{CONSIDERAÇÕES FINAIS}

Os avanços na nutrição de animais de companhia são evidentes e vários conceitos aplicados à nutrição humana nos últimos anos têm sido aplicados à nutrição dos pets. Os proprietários destes animais, em grande maioria, abandonaram as dietas caseiras e passaram a fornecer dietas comerciais balanceadas e nutricionalmente completas, sendo capazes de suprir as necessidades diárias de seus animais em todas as fases de vida.

Os proprietários de pets atualmente buscam produtos que não só sustentem nutricionalmente seus animais de estimação, mas que também proporcionem a eles uma melhor qualidade de vida.

Cães e gatos são classificados como carnívoros, porém ambos apresentam particularidades quanto as suas necessidades nutricionais de acordo com sua fase de vida, sendo os gatos considerados carnívoros obrigatórios e os cães facultativos. Logo, é de extrema importância o conhecimento das características fisiológicas e das exigências das diferentes espécies nas diferentes fases de vida para que se possa atender a demanda de um mercado que está em franca expansão, o da Nutrição de Pets.

\section{REFERÊNCIAS}

ASSOCIAÇÃO NACIONAL DOS FABRICANTES DE ALIMENTOS PARA ANIMAIS DE ESTIMAÇÃO ANFALPET. Manual do Programa Integrado de Qualidade Pet, 4a d., 612 p., São Paulo, 2010.

BORDIN, R. A. Conceitos de Alimentação ao Longo da Vida de Cães e Gatos. São Paulo: Universidade Anhambi Morumbi. Disponível em: < http://www.anhembi.br/publique/media/alimentacao_ao_longo_da_vida_animal.pdf>. Acessado em: 28 fev. 2017.

BORGES, F. M. DE O.; SALGARELLO, R. M.; GURIAN, T. M. Recentes avanços na nutrição de cães e gatos. UFPEL. 2011 Disponível em: <http://wp.ufpel.edu.br/nutricaoanimal/files/2011/03/Avan\%C3\%A7os_caes_gatos.pdf>. Acesso em: 28 fev. 2017.

BRITO, J. M. DE; FERREIRA, A. H. C.; SANTANA JUNIOR, H. A. DE et al. Probióticos, prebióticos e simbióticos na alimentação de não-ruminantes. Revista Eletrônica Nutritime. Artigo 229. v. 11, n. 01, p. 3070-3084, 2014. Disponível em: http://www.nutritime.com.br/arquivos_internos/artigos/ARTIGO229.pdf>. Acesso em: 28 fev. 2017.

CAMILO, M.; SAKAMOTO, M. I.; GOMES, M. O. S. Nutrições de cães em diferentes fases da vida. Boletinho Técnico da Universidade Camilo Castelo Branco, Departamento de Produção Animal. 18 
f. 2014. Disponível em: <http://unicastelo.br/portal/wp-content/uploads/2016/11/BOLETIM10_2014.pdf>. Acesso em: 28 fev. 2017.

CARCIOFI, A.C. Emprego de fibras em alimentos para cães e gatos. In: SIMPÓSIO SOBRE NUTRIÇÃO DE ANIMAIS DE ESTIMAÇÃO, 5, 2005, Campinas. Anais... Campinas: CBNA, 2005, p.95108.

CARCIOFI, A.C. Fontes de proteína e carboidratos para cães e gatos. Revista Brasileira de Zootecnia, v.37, p.28-41, 2008. Disponível em: http://www.scielo.br/pdf/rbz/v37nspe/a05v37nsp.pdf >, Acesso em: 28 fev. 2017.

CARCIOFI, A.C. Métodos para estudo das respostas metabólicas de cães e gatos a diferentes alimentos. Revista Brasileira de Zootecnia, v.36, p.235-249, 2007. Disponível em:<http://www.scielo.br/pdf/rbz/v36s0/22.pdf>, Acesso em: 28 fev. 2017.

CARCIOFI, A. C.; JEREMIAS, J. T. Progresso científico sobre nutrição de animais de companhia na primeira década do século XXI. Revista Brasileira Zootecnia, v.39, p.35-41, 2010. Disponível em: <http://www.scielo.br/pdf/rbz/v39sspe/05.pdf>, Acesso em: 28 fev. 2017.

CASE, L.P.; CAREY, D.P.; HIRAKAWA, D.A. Nutrição canina e felina - Manual para profissionais. Madri: Harcourt Brace de España, 1998. 424p..

FISCHER, M. Efeitos de diferentes fontes de fibra na digestibilidade de nutrientes, nas respostas metabólicas pós-prandiais e na saúde intestinal de gatos. 2011. 97 f. Dissertação (Mestrado em Zootecnia) Universidade Federal do Rio Grande do Sul, Faculdade de Agronomia, Programa de PósGraduação em Zootecnia, Porto Alegre.

FORTES, C. M. L. SÁ. Formulação de rações para cães. Anais do Zootec. Campo Grande - MS. 2005. Disponível em: <http://elementarsolucoes.com.br/wpcontent/uploads/2012/03/Formula\%C3\%A7\%C3\%A3o-de-Ra\%C3\%A7\%C3\%B5es-para-

C\%C3\%A3es.pdf>. Acesso em: 28 fev. 2017.

CAPPILLI, S.; MANICA, E.; HASHIMOTO, J. H. Importância dos aditivos na alimentação de cães e gatos: Revisão. Publicações em Medicina Veterinária e Zootecnia. v. 10, n.3, p. 212-223, 2016. https://doi.org/10.22256/pubvet.v10n3.212-223

FELICIANO, M.A.R.; SAAD, F.M.O.B.; LOGATO, P.V.R.; AQUINO, A.A.; JOSÉ, V.A.; ROQUE, N.C. Efeitos de probióticos sobre a digestibilidade, escore fecal e características hematológicas em cães. Arquivo Brasileiro de Medicina Veterinária e Zootecnia, v.61, n.6, p.1268-1274, 2009. https://doi.org/10.1590/S0102-09352009000600003

FRANÇA, J.; SAAD, F.M.O.B.; SAAD, C.E.P.; SILVA, R.C.; REIS, J.S. Avaliação de ingredientes convencionais e alternativos em rações de cães e gatos. Revista Brasileira de Zootecnia, v.40, p.222-231, 2011.

KIEFER, C. Minerais quelatados na nutrição de aves e suínos. Revista Eletrônica Nutritime, v. 2, p. 206-220, maio/junho 2005. Disponível em: < http://www.nutritime.com.br/arquivos_internos/artigos/023V2N3P206_220_MAI2005_.pdf>. Acesso 
LAZZAROTTO, J. J. Nutrição e alimentação de filhotes de cães. Revista da FZVA Uruguaiana, v. 7/8, n.1, p. 157-162. 2000.

MAIORKA, A. e OLIVEIRA, S. G. Alimentos em rações para cães e gatos. Anais Zootec 2007. Disponível

<http://www.abz.org.br/files.php?file=Alimentosfuncionaisparara esdec_esegatos_8390379 15.pdf $>$. Acesso em: 24 de novembro de 2014.

NATIONAL RESEARCH COUNCIL - NRC. Nutrient requirements of dogs and cats. Washington, D.C: National Academy Press, 2006.

NELSON, D., e Cox, M. Princípios bioquímicos de lehninger. (5a ed.) Porto Alegre: Sarvier. 2011.

OGOSHI, R. C. S.; REIS, J. S.; ZANGERONIMO, M. G.; SAAD, F. M. O. B. Conceitos básicos sobre nutrição e alimentação de cães e gatos. Ciência Animal, v. 25, n. 1, p. 64-75, 2015 (Edição Especial).

PRATS, A. Neonatologia e pediatria: canina e felina. São Caetano do Sul: Interbook, 2005.

RUIZ, D. C. A importância da nutrição do cão e do gato na senilidade. Porto Alegre: Universidade Federal do Rio Grande do Sul, Faculdade de Veterinária, 2013.

SÁ, P. G. S. Criação e manejo de cães. Rio de Janeiro: Editora FIOCRUZ, 2002.

SEIXAS, J. R. C.; ARAUJO, W. A.; FILTRIN, C. A. et al. Fontes proteicas para alimentos pet. Campinas: III Simpósio sobre Nutrição de Animais de Estimação, 2003.

SINDERAÇÕES - ANFAL, Alimentos Premium e Super Premium, Revista Clínica Veterinária, Ano VI, $N^{\circ}$ 31, Março/Abril, 2001.

SILVA, L.P.; NORNBERG, J.L. Prebióticos na nutrição de não ruminantes. Ciência Rural, v.33, n.5, p.983-990, 2003. https://doi.org/10.1590/S0103-84782003000500029

SILVA JÚNIOR, J. W.; LIMA, L. M. S.; SAAD, F. M. O. B. Fatores fisiológicos que interferem na digestão e aproveitamento do carboidrato em carnívoros domésticos. Revista Eletrônica Nutritime, v.3, $\mathrm{n}^{\circ} \quad 3, \quad$ p.331-338, 2006. Disponível em: < http://www.nutritime.com.br/arquivos_internos/artigos/033V3N3P331_338_MAl2006.pdf>. Acesso em: 28 fev. 2017.

SINDIRAÇÕES. Indústria de rações recua 0,5\% em 2009. 2009. Disponível em:<http://www.portaldoagronegocio.com.br=34754>. Acesso em: 24 de novembro de 2014.

SOUZA, P. H. M.; SOUZA-NETO, M. H.; MAIA, G. A. Componentes funcionais nos alimentos. Boletim do SBCTA, v. 37, p. 127-135, 2003.

TREVIZAN, L., e KESSLER, A. M. Lipídios na nutrição de cães e gatos: metabolismo, fontes e uso e dietas práticas e terapêuticas. Revista Brasileira de Zootecnia, v.38, p. 15-25. 2009. https://doi.org/10.1590/S1516-35982009001300002 
ROQUE, N.C.; JOSÉ, V.A.; AQUINO, A.A.; ALVES, M.P.; SAAD, F.M.O.B. Utilização da fibra na nutrição de cães. Boletim Agropecuário, Lavras: Editora UFLA, n. 70, p. 1-13, 2006. Disponível em: <http://livraria.editora.ufla.br/upload/boletim/tecnico/boletim-tecnico-70.pdf>. Acesso em: 28 fev. 2017.

WALTHAM - Benefícios dos alimentos úmidos (em sachês e em latas) para cães e gatos. Centre for Pet Nutrition. Leicestershire, 2007. Disponível em: <http://www.pedigree.com.br/>. Acesso em: 29 nov. de 2014.

WOLFARTH, D.; JOHANN, M.; ARALDI, D. A Importância de uma dieta de qualidade na alimentação de cães e gatos. XVI Amostra de Iniciação Cientifica da UNICRUZ. 2011.

WORTINGER, A. Nutrição para cães e gatos. São Paulo: Editora Roca, 2009.

YABIKU, R. M. Animais de estimação: lucros estimados, 2003. Disponível em: <http://www.bichoonline.com.br>, Acesso em: 05 nov. 2014. 